\title{
In-plane Shear Response of a Flax Fiber-epoxy Resin Composite Subjected to Repeated Loading and Creep-recovery Cycles
}

\author{
CONSTANTIN STOCHIOIU ${ }^{1}$, ANCA DECA ${ }^{1}$, ANTON HADAR ${ }^{1,2,3 *}$, HORIA GHEORGHIU ${ }^{1}$ \\ ${ }^{1}$ University Politehnica of Bucharest, 313 Splaiul Independentei, 060042, Bucharest, Romania \\ ${ }^{2}$ Academy of Romanian Scientists, 125 Calea Victoriei, 010071, Bucharest, Romania \\ ${ }^{3}$ Technical Sciences Academy of Romania, 26 Dacia Blvd, Bucharest, 010413, Romania
}

\begin{abstract}
The present paper is aimed at studying the in-plane shear response of a flax fiber - epoxy resin composite laminate. Rectangular specimens, with $\pm 45^{\circ}$ laminate orientation with respect to loading direction were used for the experimental procedure. Tensile testing up to failure allowed to extract the shear strain-shear stress curve, which have shown a linear domain, up to approximately $25 \mathrm{MPa}$, where a shear modulus was calculated, of $1.67 \mathrm{GPa}$ and a Poisson ratio of 0.7, value which is typical for off axis laminates. Strain measurement during these tests, using Digital Image Correlation, have shown that, at high stress levels, concentrators occur in the specimen in the region of failure. Repeated loading tests have shown that the material stiffens approximately $9 \%$ when increasing loading speed, leading to conclude that a viscoelastic component of the deformation is present during loading. Repeated creeprecovery tests showed that, for longer periods of time, viscoplastic deformations appear as well, with an exponential evolution with respect to the creep duration.
\end{abstract}

Keywords: shear response, creep-recovery, mechanical behavior, flax fiber

\section{Introduction}

Nowadays, society is seeing a pronounced shift in perspective, towards low emission technologies $[1,2]$, a shift that is making a mark in all areas of the industry. For the composite materials field, it is entraining the search for alternatives to the current popular options, such as carbon and glass fiber reinforcements, which are the most common reinforcements for laminate composites. Viable options are proving to be bio-based, such as the use of plant fibers, which have an innate low environmental footprint. While a great diversity exists among the proposed alternatives, studies have shown that composites with flax fiber reinforcement tend to have the best mechanical properties among the biobased reinforcement fibers [3, 4]. The low density of flax fibers, of approximately $1.5 \mathrm{~kg} / \mathrm{cm}^{3}$ [3] results in high specific strength and stiffness for the resulting material, higher than that of glass-fiber reinforced laminates [5], with which they are often compared. Furthermore, the flax plant has a long tradition of cultivation in Europe, making it an accessible local source of raw materials [6] on the continent, especially in the temperate to cold regions. Additionally, current fiber reinforced composites present a difficulty in the end-of-life cycle, pyrolysis having been proven to be the only viable method of disposal or recycling [7], a solution which alters the reinforcement fiber's mechanical properties. These arguments fuel the research for green sourced materials, with flax fiber reinforced composites, currently being on the forefront.

Several industrial applications have already been proposed, ranging from car body elements [8], to musical instruments or furniture [5]. They prove the usability of flax fiber reinforced materials for nonstructural applications. However, several unknowns are still under scope before high load applications are to be considered in an industrial scale.

The microscopic structure of the flax fibers, which broadly consists of a cellulose crystalline structure embedded in a hemicellulose matrix [9], gives it a complex mechanical response. The stress-strain curve is associated with a bi-linear or a tri-linear evolution [10,11]. Studies conducted by Keryvin et al. [12] and Charlet et al. [13] have shown that a time dependant component is present in the elementary flax fiber's mechanical behavior.

\footnotetext{
*email: anton.hadar@upb.ro
} 
Studies conducted by Poilane et al. $[14,15]$ have shown that it also is inherited by the composite material in which the fibers and introduced, regardless of fiber orientation or length. Composites with the reinforcement on the load direction have proven to display both a viscoelastic and a viscoplastic component, behavior exhibited in repeated loading-unloading and creep-recovery tests [16]. They are both recorded starting from low stress levels.

For a laminate composite to be used in conception, behavior on other directions needs to be studied as well. In a previous work, the authors have shown, using samples with $\pm 45^{\circ}$ fiber reinforcement, that in shear [17], a viscoelastic component is present, but modeling the composite behavior only considering has proven insufficient. The present work is aimed to further fuel those results, by identifying a possible viscoplastic component, through repeated loading-unloading and creep-recovery tests.

\section{Materials and methods}

The composite material used in this study is an epoxy resin reinforced with unidirectional flax fibers oriented to $\pm 45^{\circ}$, alternating and symmetrical to a middle plane. This stacking sequence allows for analyzing the in-plane shear response of the laminated material. Sheets of pre-impregnated fiber were stacked, 20 in number, and placed in a heated press. The material was manufactured using a thermocompression process at 3 bars and $130^{\circ} \mathrm{C}$ for $60 \mathrm{~min}$, followed by a post-curing cycle at $130^{\circ} \mathrm{C}$ for $60 \mathrm{~min}$, destined to eliminate residual stress caused by resin curing. From the resulting composite plates, $280 \mathrm{~mm}$ x $280 \mathrm{~mm}$ in size and approximately $3.25 \mathrm{~mm}$ thick, specimens were cut at dimensions $200 \mathrm{~mm} \times 25 \mathrm{~mm}$ (Figure 1) through a laser cutter.

The mechanical characterization was conducted in accordance with ASTM D3518 [18]. Deformation was recorded using a Dantec Dynamics Digital Image Correlation (DIC) equipment and the load was applied using an INSTRON 8872 universal testing machine (UTM), with a speed of $2 \mathrm{~mm} / \mathrm{min}$. Five specimens were selected for this procedure and painted on one of the surfaces with a stochastic pattern of black dots on a white background (Figure 2) to allow deformation recording by the DIC.

A sample, which was equipped with aluminum end tabs, was subjected to repeated loading-unloading tests, to determine the loading speed influence on the material response. Strain measurement was performed with strain gauges, as they are highly versatile in recording data with either high or low frequencies. The specimen was equipped with four transducers, two on the direction of the load and two perpendiculars to it, mounted back-to-back, as can be seen in Figure 3. Four more strain gauges on each direction, which were equipped on a dummy sample, were added to the connection, to form complete Wheatstone bridges for each of the two strain gauge directions. This type of connection was chosen to compensate for both bending and temperature-induced parasite strains. The load was applied using the same INSTRON 8872 UTM, with speeds ranging in several orders of magnitude, as can be extracted from Table 1 and data was recorded with a frequency of $50 \mathrm{~Hz}$.

At the end of each loading phase, one of the grips of the machine was opened and a period of time was allowed to pass between two consecutive tests, to permit the unhindered recovery of the sample until strain stabilization, which was continuously monitored. It is worth noting that, this modification to a regular loading-unloading test, which are common in material testing, was necessary as the unloading component of the test cycle is usually with the sample in the grips of the machine, which dictates the deformation of the sample and viciates it.

Furthermore, sample integrity was evaluated with low-stress level cycles conducted between consecutive tests. Damage appearing in the sample during loading phases would result in loss of modulus. A description of the testing procedure is presented in Figure 4.

The third type of test was that of repeated creep-recovery with a variable creep duration. The purpose was to determine how the material behaves under long periods of loading. Four cycles were conducted on the same sample, with a constant creep stress level, but increasing creep duration. The recovery period was constant, of $24 \mathrm{~h}$, considered sufficient for deformations to be stabilized. The procedure is represented in Figure 5. The strain was constantly recorded with the same method that was described for the previous test, but with a lower frequency, of $0.1 \mathrm{~Hz}$, to allow for long periods of data recording. 
Loading was managed with dead weights, amplified by a lever mechanism which enabled constant stress levels for extended periods of time.

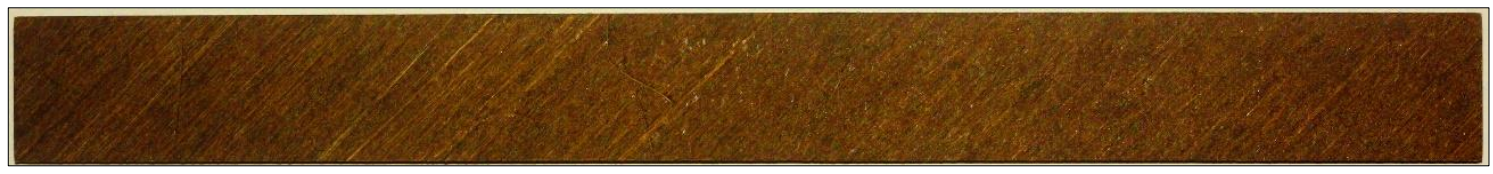

Figure 1. Composite sample

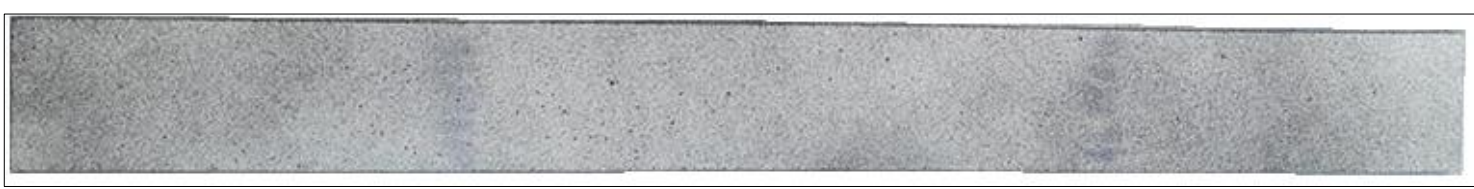

Figure 2. Sample prepared for mechanical testing

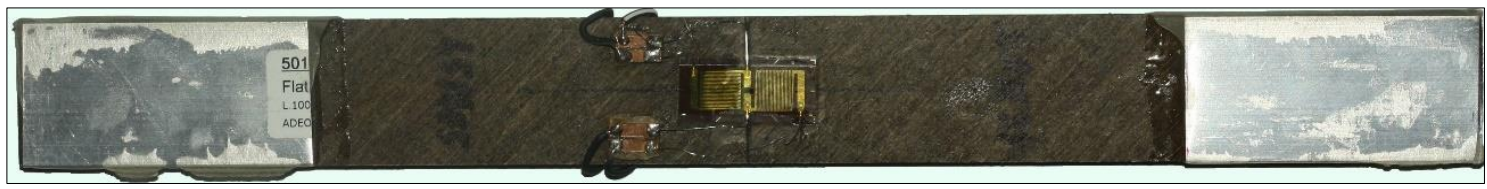

Figure 3. Sample equipped for loading-unloading and creep-recovery tests

Table 1. Repeated loading

tests parameters

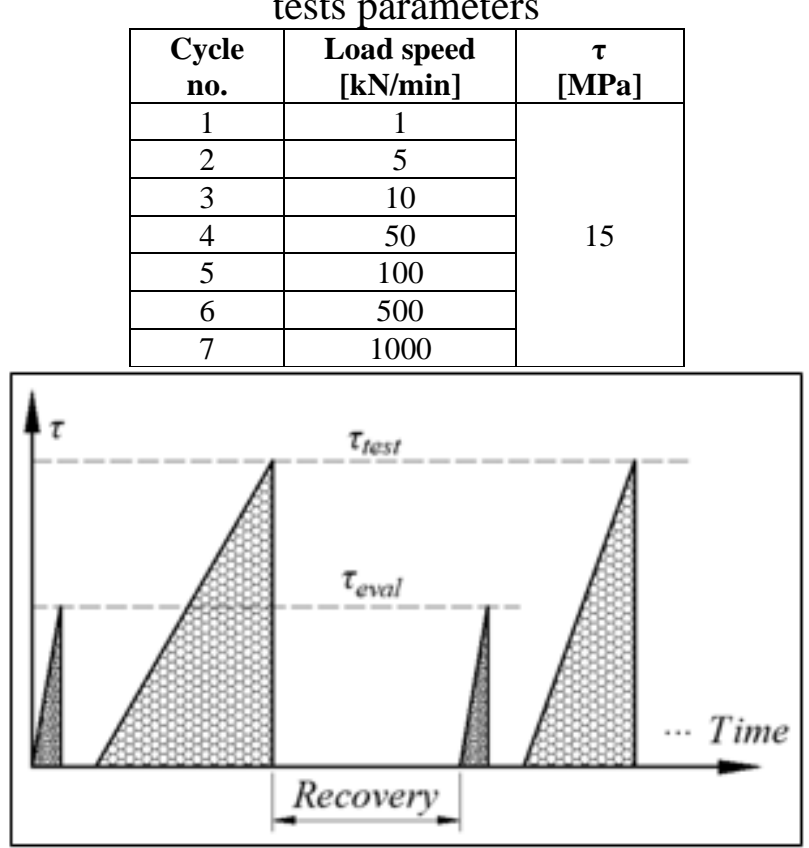

Figure 4. Repeated loading tests procedure

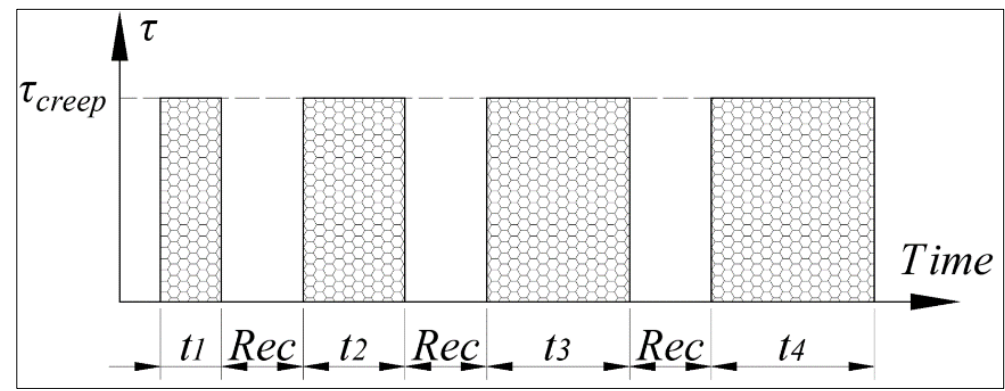

Figure 5. Repeated creep-recovery procedure 


\section{Results and discussions}

Strain data, obtained with both DIC and strain gauges was recorded on the direction of loading, or longitudinal, and perpendicular to the loading direction, or transverse. Due to the layer layup, at $\pm 45^{\circ}$ and symmetrical to a middle plane, shear strain is equal to the difference between the two, Eq. (1) and shear stress is equal to the force divided by the double of the cross-section area, Eq. (2).

\subsection{Tensile tests}

$$
\begin{gathered}
\gamma=\varepsilon_{L}-\varepsilon_{T} \\
\tau=\frac{F}{2 A}
\end{gathered}
$$

Image data collected during the tensile testing through the DIC equipment was processed with ISTRA 4D Software to calculate the deformation distribution during loading (Figure 6) which, due to geometry and ply lay-up of the sample, is uniform. From the processed data, principal strains were extracted as an average of the processed surface. They represent the longitudinal deformation, $\varepsilon_{L}$, and the transverse one, $\varepsilon_{T}$.

The deformation distribution calculated by ISTRA 4D allows to observe that, when close to rupturing, deformation distribution is no longer uniform and concentrators appear on the sample in the failure area, (Figure 7) making Eq. (1) and (2) inappropriate for shear stress and strain calculation at that level. For this reason, analysis is limited to the domain where strain distribution is uniform.

Shear strain and shear stress were plotted in Figure 8 for the five samples to obtain the characteristic curve in shear, up to 5\% shear strain, and in Figure 9 the transverse strain was plotted with respects to longitudinal strains.

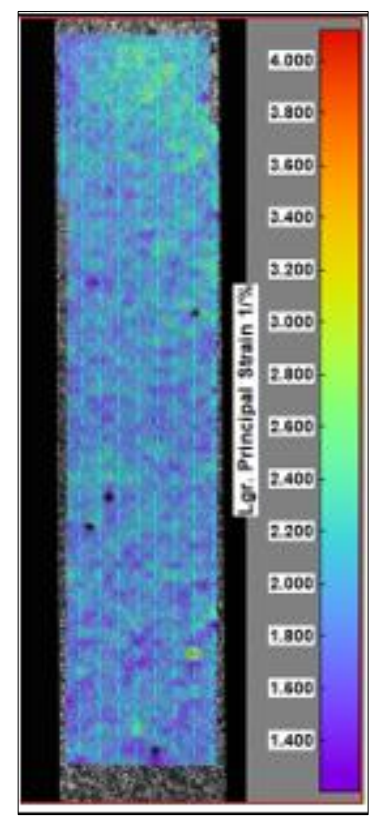

Figure 6. Example of deformation distribution during loading: principal strain 1

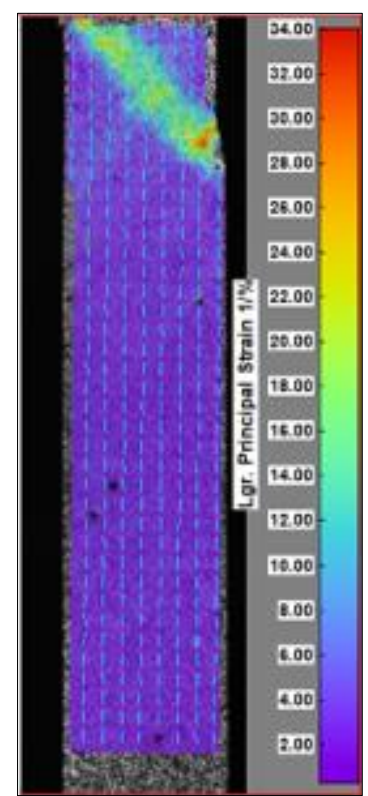

Figure 7. Concentrators at high load levels

The shear stress-strain curves show a linear domain, up to approximately $25 \mathrm{MPa}$. For this region, a chord shear modulus, $\mathrm{G}$, is calculated, between $0.2 \%$ and $0.6 \%$ shear strain, obtaining a value of $1.67 \pm 0.01 \mathrm{GPa}$. The linear region is followed by a reduction in stiffness, where the maximum shear stress is achieved, at $37.78 \pm 0.5 \mathrm{GPa}$, before failure. Longitudinal strain versus transverse strain plots shows a linear evolution, leading to the conclusion of a constant Poisson's ratio, calculated to be $0.7 \pm$ 0.01 in the same $0.2 \%-0.6 \%$ shear strain interval. It is worth noting that the value is higher than 0.5 (maximum possible value for an isotropic material) due to the layup of the reinforcement material in the matrix and is common for off-axis reinforced composites [18]. 


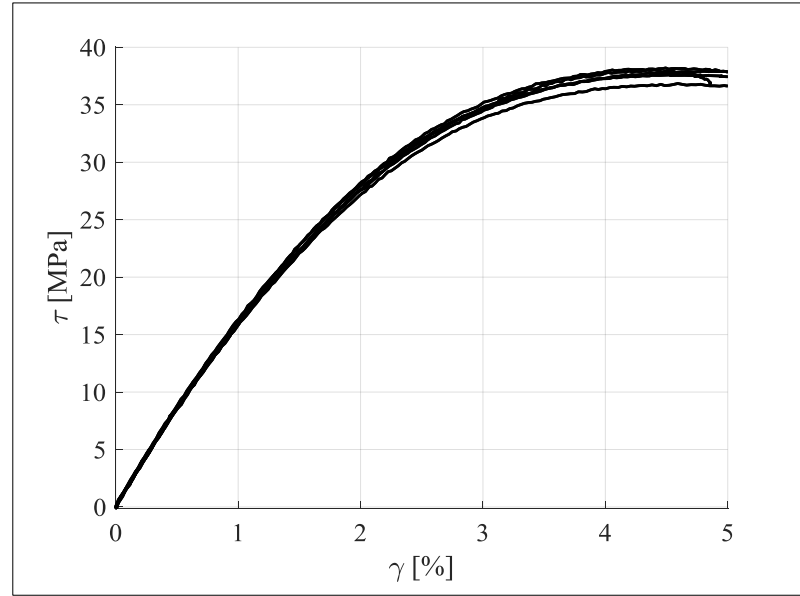

Figure 8. Shear strain - Shear stress curve

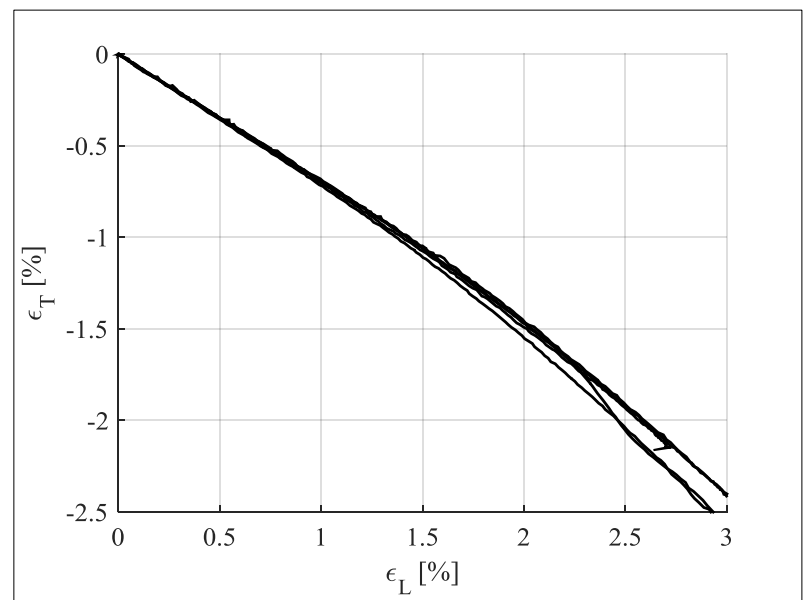

Figure 9. Longitudinal strain versus transverse strain

\subsection{Repeated loading tests}

The deformation response during the repeated loading tests is presented in Figure 10. It can be noticed that, after releasing from the grips, the sample fully recovers in a period of time. This shows the presence of a visco-elastic behavior and the absence of residual deformations. Loading phases are cut and presented in shear strain-shear stress coordinates, in Figure 11. They show a variance of the curve, dependent on loading speed, confirming that visco-elastic deformations occur during loading.

Shear modulus $\mathrm{G}$ is calculated for each curve, in the same domain as for the previously tests and is presented in Figure 12, on a logarithmic scale. An increase of approximately $9 \%$ is observed, from 1.69 $\mathrm{GPa}$ to $1.84 \mathrm{GPa}$, which stabilizes for the highest loading speeds. This leads to the conclusion that, if a sufficiently high speed is applied, a purely elastic response can be obtained. However, it can also be extracted that, in the case of high loading speeds, due to machine limitations, an overshoot is produced, which is undesirable in either laboratory conditions or industrial applications. Lastly, during the evaluation cycles, no loss in modulus has been detected, concluding that no damage has been produced in the sample.

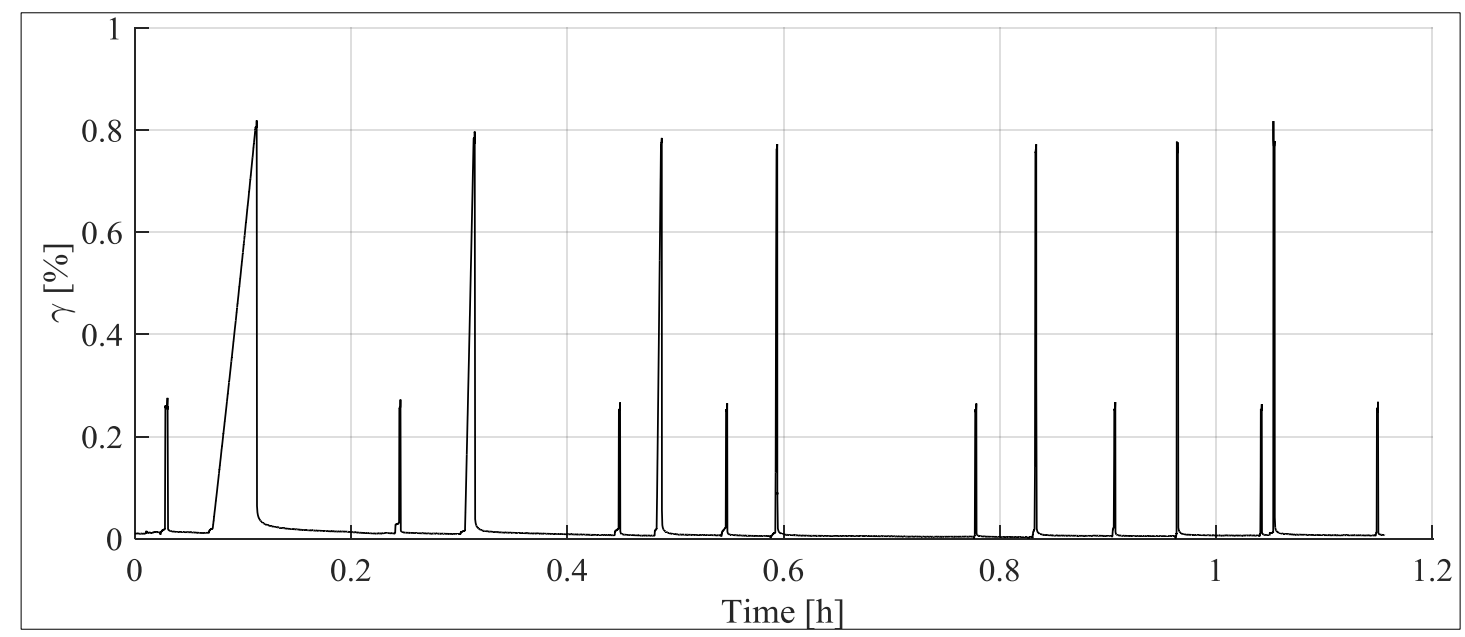

Figure 10. Deformation response during repeated loading tests 


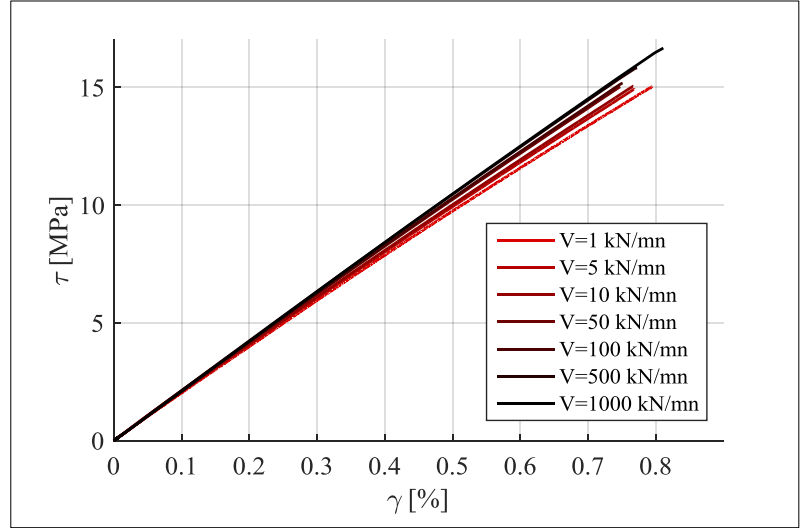

Figure 11. Shear stress-shear strain curves with respects to loading speed

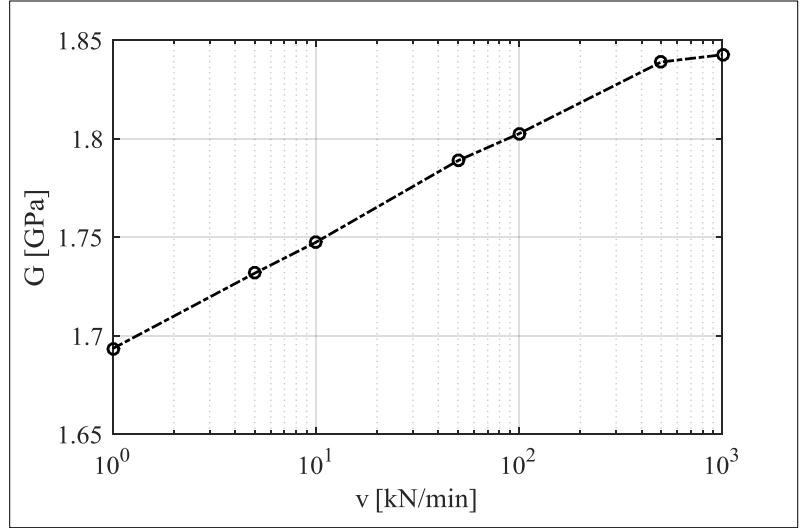

Figure 12. Shear modulus versus to loading speed

\subsection{Repeated creep-recovery tests}

The deformation response during the entire testing period is presented in Figure 13. It can be observed that a time-dependent deformation is present during creep, as expected and confirmed by the previous tests. However, at the end of each cycle, plastic deformations are present.

The recovery phases are extracted in Figure 14. Viscoelastic deformations tend to recover but, at the end of each phase, plastic deformations tend to increase. Since no load is applied during recovery, it can be concluded that they are produced by the load during creep and that they are constant during the entire recovery phase. Thus, they can be considered time-dependent plastic deformations, or viscoplastic, and that they increase with creep duration. Furthermore, it is possible to dissociate them during recovery, when viscoplastic strains are constant, but impossible during the creep phase, when they are both varying in time.

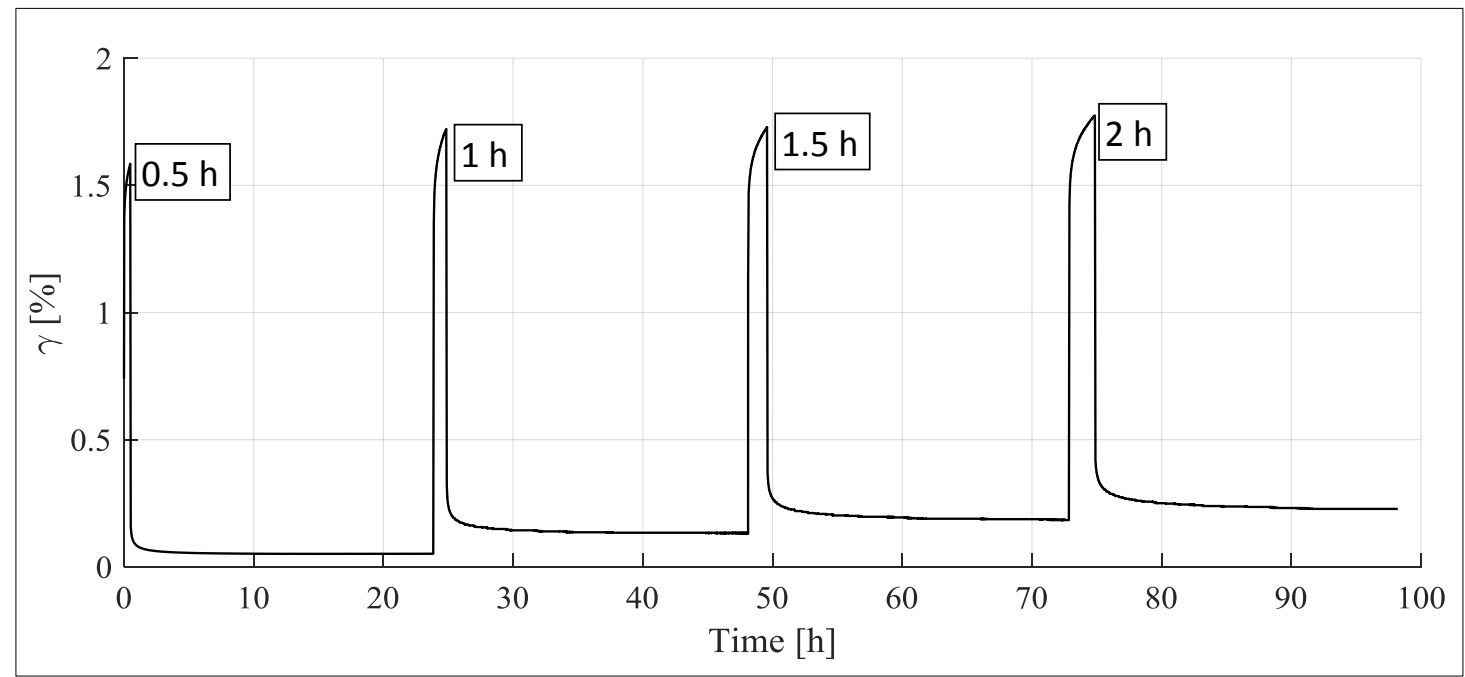

Figure 13. Shear strain response during the creep-recovery test

This viscoplastic strain, recorded at the end of the recovery phases, is depicted in Figure 15 in a logarithmic time scale, where the cumulated creep duration is used for the abscissa axis. A linear evolution can be traced, which signifies, on a linear scale, an exponential evolution with respects to time. 


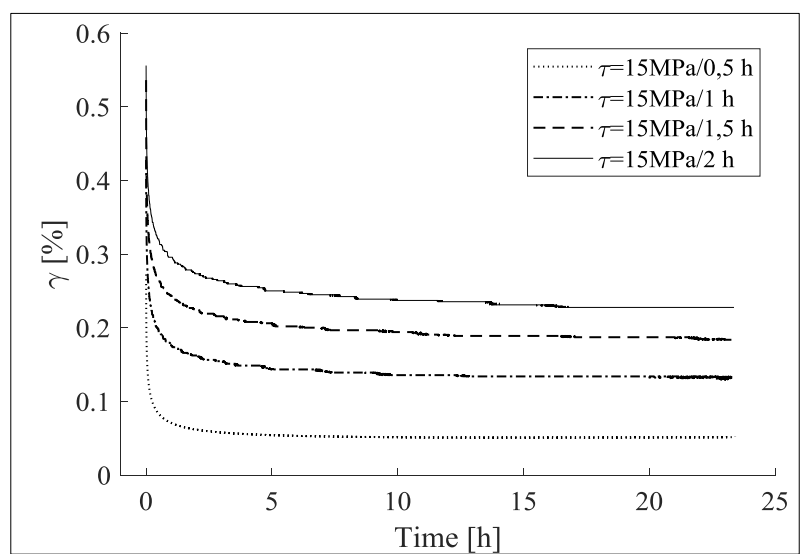

Figure 14. Recovery phases

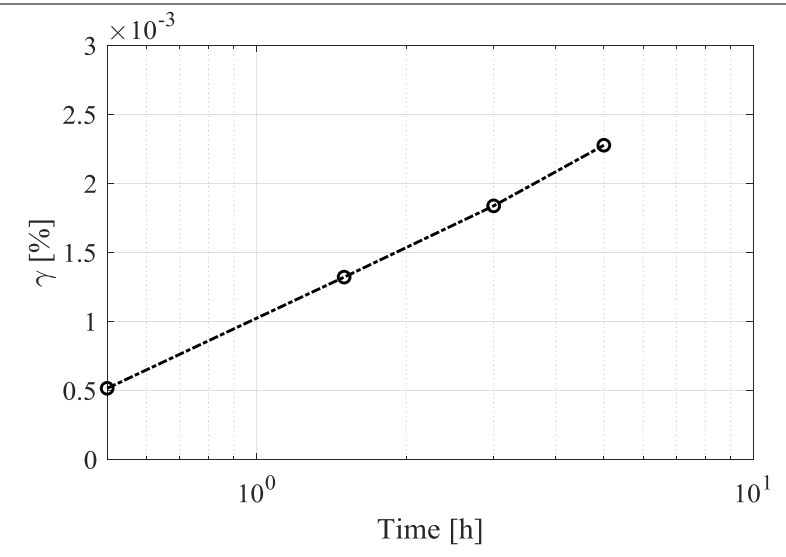

Figure 15. Cumulated plastic deformations versus cumulated creep duration

When considering the repeated loading tests and the creep recovery tests, it can be concluded that the overall shear behavior of the material is a sum of viscoelasticity and viscoplasticity, with the latter being present only when the load is maintained for a longer period of time.

These results show that a laminated composite material with flax fiber reinforcement will have a timedependent behavior even in normal environmental conditions.

\section{Conclusions}

A set of experimental data for a laminated composite of flax fiber and epoxy resin has been presented. The lay-up of the laminates, arranged at $\pm 45^{\circ}$, with respect to the loading direction and symmetrically with respect to a middle plane allowed to analyze the in-plane shear response of the material.

Through tensile testing, the shear strain - shear stress curve was extracted up to 5\% shear strain. It presents a linear domain, where a shear modulus was calculated and a transition region where maximum shear stress was extracted. The longitudinal strain versus transverse strain plot showed a linear evolution, leading to the conclusion of a constant Poisson's ratio.

The repeated loading test have shown that, by increasing the loading speed, the material stiffens, up to an asymptote, leading to the conclusion that a viscoelastic component is present in the material response, even during loading. It can be reduced and, possibly eliminated by increasing the loading speed. Furthermore, no significant plastic deformations were recorded due to the short duration of the applied loads. The creep-recovery tests showed that, for long periods of loading, plastic deformations accumulate, dependent on load duration, in an exponential evolution.

Acknowledgments: This work is supported by the project ANTREPRENORDOC, in the framework of Human Resources Development Operational Programme 2014-2020, financed from the European Social Fund under the contract number 36355/23.05.2019 HRD OP /380/6/13 - SMIS Code: 123847

\section{References}

1. *** United Nations Framework Convention on Climate Change, Paris Agreement, 2015.

2. *** EUR-Lex, Directive 2005/64/EC of the European Parliament and of the Council of 26 October 2005, Official Journal of the European Union, 2005, L 310, p. 10-27.

3. BLEDZKI A.K., REIHMANE S., GASSAN J., Properties and modification methods for vegetable fibers for natural fiber composites, Journal of Applied Polymer Science, 1996, 59(8), p. 1329-1336.

4. GAY D., Composite Materials Design and Applications, CRC press, 2016.

5. PIL L., BENSADOUN F., PARISET J., VERPOEST I., Why are designers fascinated by flax and hemp fibre composites? Composites Part A: Applied Science and Manufacturing, 2016, 83, p. 193-205. 6. FAOSTAT Report, Top 10 producers of flax for 2010-2016, 2018. 
7. JODY B.J., POMYKALA J.A., DANIELS E.J., GREMINGER J.L., A process to recover carbon fibers from polymer-matrix composites in end-of-life vehicles, JOM, 2004, 56(8), p. 43-47.

8. AKAMPUMUZA O., WAMBUA P.M., AHMED A., LI W., QIN X.H., Review of the applications of biocomposites in the automotive industry, Polymer Composites, 2017, 38(11), p. 2553-2569.

9. BOURMAUD A., BEAUGRAND J., SHAH D.U., PLACET V., BALEY C., Towards the design of high-performance plant fibre composites, Progress in Materials Science, 2018, 97, p. 347-408.

10.CHARLET K., EVE S., JERNOT J.P., GOMINA M., BREARD J., Tensile deformation of a flax fiber, Procedia Engineering, 2009, 1(1), p. 233-236.

11.LEFEUVRE A., BOURMAUD A., MORVAN C., BALEY C., Elementary flax fibre tensile properties: Correlation between stress-strain behaviour and fibre composition, Industrial Crops and Products, 2014, 52, p. 762-769.

12. KERYVIN V., LAN M., BOURMAUD A., PARENTEAU T., CHARLEUX L., BALEY C., Analysis of flax fibres viscoelastic behaviour at micro and nano scales, Composites Part A: Applied Science and Manufacturing, 2015, 68, p. 219-225.

13. CHARLET K., Contribution à l'étude de composites unidirectionnels renforcés par des fibres de lin : relation entre la microstructure de la fibre et ses propriétés mécaniques, Thèse de Doctorat, Université de Caen/Basse-Normandie, 2008.

14. POILÂNE C., Z. CHERIF E., RICHARD F., VIVET A., BEN DOUDOU B., CHEN J., Polymer reinforced by flax fibres as a viscoelastoplastic material, Composite Structures, 2014, 112(1), p. 100-112. 15.VARNA J., ROZITE L., JOFFE R., PUPURE A., Non-linear behaviour of PLA based flax composites, Plastics, Rubber and Composites, 2012, 41(2), p. 49-60.

16. STOCHIOIU C., GHEORGHIU H.M., ARTIMON F.P.G., Visco-elastoplastic characterization of a flax-fiber reinforced biocomposite, Mater. Plast., 58(1), 2021, p. 78-84.

17. STOCHIOIU C., PIEZEL B., CHETTAH A., FONTAINE S., GHEORGHIU H.M., Basic modeling of the visco elastic behavior of flax fiber composites, Industria Textila, 2019, 70(4), p. 331-335.

18. ***STANDARD A.S.T.M. D3518/D3518M-94, Standard Test Method for In-Plane Shear Response of Polymer Matrix Composite Materials by Tensile Test of a $\pm 45^{\circ}$ Laminate, Annual Book of ASTM Standards, 2007, 94, p. 1-7.

Manuscript received: 2.12.2021 